\title{
$\$$ Research Square \\ Hydrothermal Assisted Synthesis and Biological Evaluation of Biogenic Silver Nanoparticles
}

\section{Anthony Ekennia ( $\nabla$ chemisttony@gmail.com )}

Federal University Ndufu Alike https://orcid.org/0000-0002-3324-7566

\section{Dickson N. Uduagwu}

Federal University, Ndufu-Alike

Njemuwa N. Nwaji

Federal University, Ndufu-Alike

Olawale J. Olowu

Federal University, Ndufu-Alike

Obianuju L. Nwanji

Federal University, Ndufu-Alike

David Agwu Udu

Federal University, Ndufu-Alike

Sonde U. Christopher

Federal University, Ndufu-Alike

Obinna 0. Oje

Federal University, Ndufu-Alike

Tyopine A. Andrew

Federal University, Ndufu-Alike

Joseph E. Inya

Federal University, Ndufu-Alike

\section{Chidimma Nwosa}

Federal University, Ndufu-Alike

\section{Research Article}

Keywords: Silver, Nanoparticles, Alchornealaxiflora, Photocatalysis, Tyrosinaseinhibition

Posted Date: April 21st, 2021

DOl: https://doi.org/10.21203/rs.3.rs-441506/v1

License: (9) (1) This work is licensed under a Creative Commons Attribution 4.0 International License. 



\title{
Hydrothermal assisted synthesis and biological evaluation of biogenic silver nanoparticles
}

\author{
*Anthony C. Ekennia ${ }^{1}$; Dickson N. Uduagwu ${ }^{1}$; Njemuwa N. Nwaji ${ }^{1}$; Olawale J.Olowu ${ }^{1}$; \\ ChidimmaNwosa $^{1}$ : Obianuju L. Nwanji ${ }^{1}$; David Agwu Udu ${ }^{2}$; Sonde U. Christopher ${ }^{1}$; Obinna O. \\ $\mathrm{Oje}^{3}$; Tyopine A. Andrew ${ }^{1}$; Joseph E. Inya ${ }^{2}$ \\ ${ }^{1}$ Department of Chemistry, Alex Ekwueme Federal University, Ndufu-Alike, \\ Ebonyi State, Nigeria. \\ ${ }^{2}$ Department of Science Education, Alex Ekwueme Federal University, Ndufu-Alike, \\ Ebonyi State, Nigeria. \\ ${ }^{3}$ Department of Biochemistry and Mol. biology, Alex Ekwueme Federal University, \\ Ndufu-Alike, Ebonyi State, Nigeria.
}

\begin{abstract}
We report on hydrothermal synthesis of biogenic silver nanoparticles (AgNPs) using aqueous leaf extract of Alchornea laxiflora for threefold applications in antibacterial screening against Escherichia coli and Staphylococcus aureus, tyrosinase inhibition of mushroom tyrosine enzymes with 3,4-dihydroxyphenylalanine as a substrate and photocatalytic degradation of malachite green dye. The mode of action for the tyrosinase application and kinetics of both the tyrosinase and photocatalytic activities were provided. The localized surface resonance bands of the AgNPs were observed within the range of $424-435 \mathrm{~nm}$ from the electronic spectral analysis. Fourier transform-infrared studies reveal the functional groups of plant metabolites such as phenolic compounds and amines on the nanoparticles. The Energy Dispersive X-ray result reveals the presence of silver and other elemental compositions from the plant extract. Xray diffraction result showed a face-centred cubic crystalline structure for the AgNPs. The SEM analyses reveal that the nanoparticles are spherical in shape with average size range of 20-52 $\mathrm{nm}$. The AgNPs exhibited a dose dependent tyrosinase inhibition activity with $\mathrm{IC}_{50}$ of $20.83 \mu \mathrm{g} / \mathrm{ml}$ and a competitive mode of inhibition. The results of photocatalytic degradation of malachite green dye depicted rapid photo inspired degradation of $86 \%$ in less than a min and at reaction rate of $0.136 \mathrm{~min}^{-1}$. The silver nanoparticles showed enhanced antibacterial activities compared to the precursors: silver nitrate and aqueous extract of Alchornea laxiflora.
\end{abstract}

Keywords: Silver; Nanoparticles; Alchornealaxiflora; Photocatalysis; Tyrosinaseinhibition 


\subsection{INTRODUCTION}

About 50,000 tons of dyes are inappropriately discharged into the environment by textile, paint and other related industries due to incomplete exhaustion of dyes onto different products from aqueous dyeing processes[1]. This has overtime increased the environmental pollution in most industrialized cities around the world. More so, these dyes are non-biodegradable under aerobic conditions, toxic to aquatic life and mutagenic to humans [2]. Under anaerobic situations, azo dyes can be broken down to aromatic amines that are more toxic than the larger dye molecule under a process that is kinetically very slow, thereby causing more harm to human and aquatic animals. In view of these facts, there are efforts to adopt techniques that will either completely recover the dye molecules from wastewater or mineralize the dyes to oxidation end points like $\mathrm{CO}_{2}, \mathrm{H}_{2} \mathrm{O}, \mathrm{NO}_{3}{ }^{-}, \mathrm{SO}_{4}{ }^{2-}$ and $\mathrm{Cl}^{-}[1]$. Techniques such as flocculation, electrocoagulation, redox treatment, coagulation, incineration and activated carbon sorption have been successfully applied; however, due to composition diversity, high colour intensity and toxicity of industrial wastewater, they have fallen short. Hence, there are enormous pressures on industries to satisfy stringent environmental measures on disposable industrial wastes as it concerns coloured liquid wastes [3].

Photocatalytic degradation method has gained lots of attention due to its low cost, high chemical stability, high rate of degradation and successful mineralization of the dye molecules to nontoxic oxidation byproducts [4]. Metal nanoparticles and their metal oxide analogs have been reported as useful inorganic catalysts in the degradation of various organic dye pollutants in the presence of an illumination source [1]. Several methods are employed in the synthesis of metal nanoparticles. However, plant mediated synthesis of metal nanoparticles have gained a lot of interest in recent times due to its ease of synthesis, use of benign reducing and stabilization agents, distinctive (size, shape and dispersion) properties of the metal nanoparticles obtained from diverse plant sources and the production of less toxic metal nanoparticles for medicinal and cosmetic applications [5]. Silver nanoparticles have gained the most attention among other noble metal nanoparticles due to its high electrical and thermal conductivity, less lethal, wide range of optical absorption capacity, less expensive, surface enhanced Raman scattering, high chemical stability, high photocatalytic activity and nonlinear optical behaviour [6]. Biosynthesized silver nanoparticles have been reported as antimicrobial, water sterilizing, wound healing, lavicidal and 
anticancer agents [7]. Besides their medical and pharmacological applications, they are widely used as catalyst in the photodegradation of organic dye pollutants, imaging agents in biomedical devices, and as sensors in optical and microelectronic materials [8]. Plant sources such as Mimosa pigra[9], Morindutinctoria, Trigonellafoenum-graecm[10] and Hypneamusciformis[11]have been used to obtain silver nanoparticles with varied physicochemical properties. Biogenic silver nanoparticles, obtained from various plant sources have been reported as efficient photocatalysts in the degradation of various organic dyes [5, 12]. However, to the development of photocatalysts that will enthuse fast and efficient degradation process of organic dye pollutants and also exhibit high chemical stability and low toxicity, has sustained current research in photocatalysis.

Biogenic silver obtained from extracts of Hovenia dulcis fruit extract [13] and zinc oxide nanoparticles obtained from brown seaweed of Turbinaria conoides[14] have been reported to exhibit tyrosinase inhibition. Tyrosinase inhibition is an efficient mechanism in the treatment of skin diseases of hyperpigmentation such as melasma, freckles, age spots and senile lentigo [15]. Synthetic tyrosinase inhibitors have been associated with some adverse effects such as erythema and contact dermatitis. Hence, there is need to develop tyrosinase inhibitors from less lethal materials that are cost effective, non toxic and potent. Very few works have been reported on tyrosinase inhibition activity of silver nanoparticles, and their mechanism of action is grossly under reported [15]. In our previous works we investigated the melanogenesis inhibition potential of biogenic zinc oxide nanoparticles obtained from aqueous extract of Alchornea laxiflora [16]. The result showed better melanogenesis inhibition compared to that of zinc oxide nanoparticles of brown seaweed of Turbinaria conoides. However we intend to utilize the numerous biological potentials of silver nanoparticles and those of Alchornea laxiflora extracts in antibacterial, tyrosinase inhibition and photodegradation studies.

Alchornea laxiflora is a shrub that belongs to the family of Euphorbiaceae that can be found in the tropical rain forest of countries such as Nigeria, Ethiopia, and Zimbabwe. Phytochemical screening of aqueous extract of Alchornea laxiflora leaves has shown the presence of polyphenols, alkaloids and flavonoids. Biological potentials of the plant extract have been reported as antimicrobial [17] and antioxidant [18] activities. The plant is used traditionally in the treatment of many diseases such as pile, Dysentery, Malaria, Eczema, Cough and High fever 
[19]. The reducing and stabilizing potentials of the phytochemicals of Alchornea laxiflora have been exploited in plant mediated synthesis of various nanoparticles such as zinc oxide [14] and copper [20]. The biogenic copper nanoparticle was reported to show high catalytic activity in the oxidative desulphurization of model oil. The zinc oxide nanoparticles showed good photodegradation of Congo red dye and tyrosinase inhibition activity [20].

In this study, we intend to report plant mediated synthesis of silver nanoparticles (AgNPs) obtained from aqueous leaf extract of Alchornea laxiflora. The antibacterial potentials of the nanoparticles will be investigated, taking advantage of the established antibacterial properties of silver nanoparticles and the plant extract [17]. We will carry out studies on the degradation of Malachite green dye solution using the biogenic silver nanoparticles as photocatalyst. In addition, the tyrosinase inhibition activity of the AgNPs will be investigated and compared to previous studies. The mode of tyrosinase inhibition will be established using Line-weaver Burk model.

\section{EXPERIMENTAL SECTION}

2.1 Materials: All the chemicals \& reagents were analytical grade (AR) and used without further purification. The fresh plant leaves (Alchornea laxiflora) were collected from Ikwo in Ebonyi State, Nigeria. Sodium hydroxide, ascorbic acid, sodium phosphate dibasic heptahydrate, sodium phosphate monobasic monohydrate, Silver nitrate $\left(\mathrm{AgNO}_{3}\right)$, Mushroom tyrosine enzyme (25KU), 3,4-Dihydroxy-L-phenylalanine (L-DOPA) and Malachite green dye were obtained from Sigma-Aldrich.

Apparatus and instrumentation: Microscopic characterization: The surface morphology, size and elemental composition of the AgNPs were investigated by scanning electron microscope (SEM) and Energy Dispersive X-ray analysis (EDS) (FEIXL 30, Model). X-ray diffraction (XRD) was carried out to determine the crystalline nature of the AgNPs using Brukers D8 Discover diffractometer, equipped with a Lynx Eye detector, under $\mathrm{Cu}-\mathrm{Ka}$ radiation $(1=1.5405$ $\AA$ A). Optical characterization: the Ultraviolet-visible spectra were analyzed with Agilent Technologies Cary 60 spectrophotometer and the Fourier transform-infrared (FTIR) spectra were recorded on Agilent Technologies spectrophotometer. 


\subsection{Methods}

\subsubsection{Preparation of aqueous leaf extracts of Alchornea Laxiflora}

The leaves of Alchornea laxiflora were freshly collected from Ikwo in Ebonyi State, Nigeria. They were plucked from the stem and dried for about four weeks at room temperature. The dry leaves were grinded into fine particles using a blender. $3 \mathrm{~g}$ of the finely ground leaf particles were dissolved in $300 \mathrm{~mL}$ of deionized water in a $500 \mathrm{~mL}$ flat bottom flask and was heated using a water bath for about $45 \mathrm{~min}$ at a temperature of $65^{\circ} \mathrm{C}$. The mixture was allowed to cool and filtered using a mesh cloth. The filtrate was further filtered using whatman filter paper under vacuum. The resulting leaf extracts of Alchornea laxiflora were stored in an amber bottle and kept in a refrigerator.

\subsubsection{Synthesis of Silver nanoparticles using leaves extract}

Silver nitrate salt $(10 \mathrm{mM})$ was weighed and dissolved in $99 \mathrm{~mL}$ of deionized water. The solution was heated to ensure complete dissolution. $1 \mathrm{~mL}$ of the plant extract was added in drops to the stirring solution of the silver salt. The mixture was magnetically stirred and the formation of the silver nanoparticles was monitored using UV-Vis spectrophotometer at different time intervals $(5,15,30,45,60$ and $90 \mathrm{~min})$. At the end of each reaction, the AgNPs solution was centrifuged at $4000 \mathrm{rpm}$ for $30 \mathrm{~min}$ to make the solution crystal-clear. The effect of volume of the plant extract on the formation of the silver nanoparticles was also carried out by varying the concentration of the plant extracts $(1.5$ and $2 \mathrm{~mL})$ and keeping the concentration of the silver salt at $10 \mathrm{mM}[21]$.

\subsubsection{Antibacterial studies}

Clinical isolates of different microbial strains were collected from Department of Microbiology, Alex Ekwueme Federal Teaching Hospital, Abakaliki, Nigeria. The bacteria strains were Gram negative (Escherichia coli) and Gram positive (Staphylococcus aureus). The microbes were chosen based on their clinical and pharmacological relevance [22]. Antibacterial screening was carried out using agar disk diffusion method. The petri plates were prepared using sterile MullerHinton agar(MHA). The inocula of test cultures $\left(10^{6} \mathrm{CFU} / \mathrm{mL}\right)$ were streaked onto the condensed Muller Hinton agar in petri plates using a sterilized cotton swab, in order to ensure a uniform thick lawn or layer of growth, and allowed to dry for 15 min. Stock solutions of AgNPs of $(0.5$, 
$1,3,5,10 \mu \mathrm{g} / \mathrm{mL}$ ) concentrationof AgNPs stock solutions was prepared using $100 \%$ dimethylsulfoxide (DMSO) as diluent and the various concentrations were also used for minimum inhibitory concentration (MIC). The stock solutions $(10 \mu \mathrm{g} / \mathrm{mL})$ of the plant extract, $\mathrm{AgNO}_{3}$ and standard drug were prepared using double distilled water at the same concentration as the nanoparticles. Sample dilutions were performed as described by the NCCLS. Blank paper disks with a diameter of $6.0 \mathrm{~mm}$ were impregnated with $25 \mu \mathrm{L}$ of the AgNPs stock solution. About $20 \mu \mathrm{L}$ of $1.25 \mathrm{mg} / \mathrm{mL}$ 3-(4, 5-dimethylthiazol-2-yl)-2, 5-diphenyltetrazolium bromide (MTT)(Sigma-Aldrich) was added to each plate and observed for a purple colouration after incubation at $37^{\circ} \mathrm{C}$ for $30 \mathrm{~min}$, which indicated microbial growth. The plates were incubated for $24 \mathrm{~h}$ at $37{ }^{\circ} \mathrm{C}$ with the bacteria strains. Control experiments were carried out under similar condition by using commercially available antibacterial drug (Streptomycin) as the positive control drug, while dimethylsulfoxide was used as a negative control. The sensitivities ofthe microbes to the samples were determined by measuring the sizes of inhibitory zones (including the diameter of disk) on the agar surface around the disks, and values $<6 \mathrm{~mm}$ were considered as not active against microorganisms. Zones of inhibition were recorded in millimetres and the experiment was repeated twice. Experimental results were given as mean \pm S.D. of the two parallel measurements [23].

\subsubsection{Photocatalytic degradation of Malachite Green dye}

In the catalytic experiment, $8 \mathrm{mg}$ of AgNPs was dispersed into a freshly prepared solution containing $100 \mathrm{~mL}$ of deionized water and $1.5 \mathrm{mg}$ of Malachite green dye. The solution was stirred vigorously in the dark for $15 \mathrm{~min}$ to ensure equilibration. After that, it was exposed to illumination from sunlight while stirring. The reaction was monitored by UV-Vis absorption spectra at different time $(0,5,15,30,45,60 \mathrm{~min})$ intervals [24]. The percentage degradation was obtained using the equation:

Percentage degradation $(\%)=C-\frac{S}{C} x \frac{100}{1}$

where $\mathrm{C}$ is absorbance of blank solution (dye solution) after incubation, $\mathrm{S}$ is absorbance of sample solution (dye and nanoparticles) after incubation. 


\subsubsection{Tyrosinase inhibition activity}

Briefly, $100 \mu \mathrm{g} / \mathrm{mL}$ of AgNPs was introduced to a reaction mixture containing, $0.1 \mathrm{mM}$ of 3,4dihydroxyphenylalanine (L-DOPA, $0.8 \mathrm{~mL})$ and $0.1 \mathrm{mM}$ of sodium phosphate buffer $(1.2 \mathrm{~mL}$,

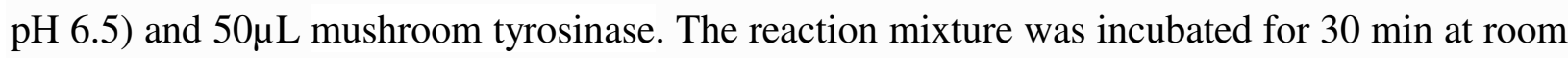
temperature. Subsequently, the formation of dopachrome was monitored by taking the absorbance of the mixture at $475 \mathrm{~nm}$ using UV-visible spectrophotometer. The experiment was repeated using other concentrations $(500 \mu \mathrm{g} / \mathrm{mL}, 300 \mu \mathrm{g} / \mathrm{mL}, 200 \mu \mathrm{g} / \mathrm{mL}$ and $50 \mu \mathrm{g} / \mathrm{mL}$ ) of AgNPs [25].

The percentage of the inhibition of tyrosinase activity was calculated by the following equation:

Tyrosinase inhibitory activity $(\%)=A-\frac{B}{A} x \frac{100}{1}$

where A is absorbance of blank solution after incubation, B is absorbance of sample solution after incubation.

The extent of inhibition by the test compounds was expressed as the percentage of concentration necessary to achieve 50\% inhibition $\left(\mathrm{IC}_{50}\right)$. The effect of the substrate was monitored in the presence and absence of the AgNPs using different concentrations $(0.5,0.75,1.25$ and $1.5 \mathrm{mM})$ of L-DOPA. Ascorbic acid was used as a reference inhibitor and for negative tyrosinase inhibitor; phosphate buffer was used instead of the inhibitor solution.

\subsection{RESULTS AND DISCUSSIONS}

\subsection{Synthesis}

Plant metabolites of aqueous extract of Alchornea laxiflora such as polyphenols, alkaloids and flavonoids[26] have high reducing capacities that can facilitate the donation of electron to $\mathrm{Ag}^{+}$to obtain $\mathrm{Ag}^{0}$. The affinity of these metabolites for silver makes them good chelating/stabilizing agents for stabilization of AgNPs. The hydrothermal synthesis of biogenic silver nanoparticles using aqueous extract of Alchornea laxiflora and $\mathrm{AgNO}_{3}$ was monitored using spectrophotometric methods to obtain the surface plasmon resonance (SPR) band of silver nanoparticles. However, change in colour of the reaction solution from dark brown to yellowish 
brown after 5 min of reaction time gave early signs of the formation of silver nanoparticles in accordance to literature reports [27].

\subsection{Absorption Spectra/Optical properties of silver nanoparticles}

The absorption of Uv-Vis radiation by nanoparticles at different wavelengths provides an indication of particle size, while the breadth of the peaks signifies the particle size distribution [13]. In the study, using $2 \mathrm{~mL}$ of aqueous extract of A.laxiflora showed the appearance of a surface plasmon band at $435 \mathrm{~nm}$ in the UV-Vis spectrum at 5min of reaction (AgNPs@5min). The SPR band had hypsochromic shifts to $432 \mathrm{~nm}, 427 \mathrm{nmand} 424 \mathrm{~nm}$ at $15 \mathrm{~min}$ (AgNPs@15min),30min (AgNPs@30min) and 45min (AgNPs@45min) of reaction respectively. However, the SPR band was observed to have a bathochromic shift to $427 \mathrm{~nm}$ at $60 \mathrm{~min}$ (AgNPs@60min) as the reaction proceeded (Fig 1).

Figure 1: Effect of reaction time on the optical properties of the silver nanoparticles.

The variation of the SPR band with time could be attributed to change in the physicochemical characteristics (such as size, shape and surface defects) of the silver nanoparticles as the reaction time increases. The absorption intensity was highest at $45 \mathrm{~min}$ of reaction and was taken as the optimal time for the formation of silver nanoparticles using $2 \mathrm{~mL}$ of aqueous leaf extract of $A$. laxiflora.

The volume of the extract of A.laxifloranin the reaction vessel was reduced to $1.5 \mathrm{~mL}$ to investigate the effect of the volume of plant extract on the optical properties of the nanoparticles (Fig 2). The surface plasmon resonance band was observed at 417 nmshowing a hypsochromic shift at $45 \mathrm{mins}$ reaction time. However, the absorption intensity of SPR band was highest for that of $2 \mathrm{~mL}$ of plant extract when compared to $1.5 \mathrm{~mL}$ volume of plant extract used. Hence, it was adopted as the optical condition for the synthesis of silver nanoparticles using A.laxiflora.

Figure 2: Effect of volume of leaf extract of Alchornealaxifloraon SPR band of the silver nanoparticles at $45 \mathrm{~min}$ reaction time. 
The surface plasmon resonance bands of the silver nanoparticles in this study were within the range as those reported in literature [28, 29], hence supporting the formation of the biogenic silver nanoparticles.

\subsection{Fourier Transform Spectra}

Fourier transform spectroscopic characterization of biosynthesized nanoparticles is used to establish likely functional groups of plant metabolites that are bound specifically on the surface of silver nanoparticles which participate in the reduction and stabilization of the nanoparticles. Fig. 3a and 3b show Fourier Transform Infrared spectroscopy (FT-IR) spectra of aqueous leaf extract of Alchornea laxiflora and silver nanoparticles.

\section{Figure 3: (a) FT-IR spectrum of aqueous leaf extract of Alchornea laxiflora (b) FT-IR spectrum of silver nanoparticles (AgNPs@5min).}

The FT-IR results show the presence of hydroxyl groups at 3269 and $3267 \mathrm{~cm}^{-1}$ in the spectra of the plant extract and nanoparticles respectively. The hydroxyl groups could be presumably attributed to the presence of polyphenols, alkaloids and flavonoids metabolites of the plant extract and which can also be found on the surface of AgNPs as capping agents. An intense peak was also seen at $1638 \mathrm{~cm}^{-1}$ in both spectra which is due to stretching vibration of carbonyl group presumably from alkaloids, flavonoid and terpenoids metabolites on the surface of the silver nanoparticles. It is presumed that through the interaction of carbonyl and hydroxyl groups of plant metabolites of A.laxiflora with the surface of the silver nitrate in the absence of other strong reducing and capping agents, both reduction and stabilization occurred leading to the formation of silver nanoparticles [13].

\subsection{Elemental composition/Energy Dispersive $X$-ray}

Energy dispersive X-ray analysis (EDX) is used to identify elemental compositions on the surface of the metallic nanoparticles. The result supports the presumptions made from the results of the FT-IR spectra. The EDX result presented in Figure 4 reveals strong signal in the silver region thus confirming the formation of AgNPs. The carbon signal could also be attributed to plant metabolites on the surface of the nanoparticles. 


\section{Figure 4: Energy dispersive X-ray of silver nanoparticles(AgNPs@5min)}

The presence of Si is possibly due to carbon coated silica grid used for sample preparation [30].

\subsection{Scanning Electron Microscope}

The surface morphology and sizes of different silver nanoparticles obtained from different reaction durations $(5,15,30$ and $45 \mathrm{~min})$ were investigated and their scanning electron microscopic images presented at Fig 5.

Figure 5: Scanning electron microscopic images of different silver nanoparticles(a).AgNPs@5min(b).AgNPs@ 15min (c).AgNPs@ 30min (d).AgNPs@ 45min (Scale bar: 100nm).

The results show that the nanoparticles are spherical with an average size of $20 \mathrm{~nm}, 45 \mathrm{~nm}, 47 \mathrm{~nm}$ and $52 \mathrm{~nm}$ at varying duration of reaction of 5, 15, 30 and $45 \mathrm{~min}$ respectively. This can be attributed to the increase in the number of nanoparticles and agglomeration[31].

\subsection{X-Ray Diffraction}

The XRD was used in order to confirm the crystallinity of the biogenic silver nanoparticles (AgNPs@ 45min). The result was presented in Fig. 6.

\section{Figure 6: X-Ray Diffraction of silver nanoparticles (AgNPs@ 5min)}

TheXRD diffraction patterns gavesome well-defined crystalline peaks assigned to the 111, 200, 220, 311 and 222 planes. The peaks are characteristic of the face-centred cubic structures of metallic silver nanoparticles [32]. The XRD sizes of the nanoparticles were calculated using the Debye-Scherrer equation, eqn (3)

$D=\frac{k \lambda}{\beta \cos \theta}$

where $\lambda$ is the wavelength of the X-ray source $(1=1.5405 \AA), \mathrm{k}$ isan empirical constant equal to $0.9, \beta$ is the full width at half maximum of the diffraction peak and $\theta$ is the angular position. The observed sizes for different time ranges were from $18-20 \mathrm{~nm}$ in agreement with the observed size using SEM for AgNPs@5min. 


\subsection{Tyrosinase inhibitory activity}

The tyrosinase inhibitory activity of the silver nanoparticles against mushroom tyrosinase as a representative enzyme and L-DOPA as a substrate was investigated and compared to those of the plant extract and ascorbic acid (standard drug). In a preliminary screening at $100 \mu \mathrm{g} / \mathrm{mL}$, the silver nanoparticles showed significant inhibition (55\%) of tyrosinase L-DOPAoxidation compared to $\mathrm{AgNO}_{3}(17 \%)$ and plant extract $(40 \%)$. The results of the screening at other concentrations of silver nanoparticles $(50-500 \mu \mathrm{g} / \mathrm{mL})$ are presented in Fig 7 and show dose dependent activity with $\mathrm{IC}_{50}$ of $20.83 \mu \mathrm{g} / \mathrm{mL}$.

\section{Fig 7: Tyrosinase inhibitory activity of AgNPs}

The tyrosinase inhibitory activity of the plant extracts can be attributed to chelation of copper ions in mushroom tyrosinase by hydroxyl groups of phenolic compounds or flavonoids present in the extract [33]. The enhanced tyrosinase activity of AgNPs compared to the plant extracts and $\mathrm{AgNO}_{3}$ could be attributed to the presence of plant metabolites on the surface of the nanoparticles and an increased surface area for chelation of copper ions in mushroom tyrosinase. The results of the tyrosinase inhibitory screening in this study for AgNPsarebetter than those obtained from tyrosinase inhibitory screening for AgNPs and ZnONPsfrom extracts of Artemisia аппиа and seaweed-turbinaria conoides, which gave $40 \%(100 \mathrm{mg} / \mathrm{mL})$ and $50 \%(100 \mu \mathrm{g} / \mathrm{mL})$ respectively $[13,14]$. The results of tyrosinase inhibitory activity of AgNPs $(20.83 \mu \mathrm{g} / \mathrm{mL})$ was also better than those we had reported for ZnO-NPs (obtained from aqueous leaf extracts of A.laxiflora) with $\mathrm{IC}_{50}$ of $66.28 \mu \mathrm{g} / \mathrm{mL}$ [14] and AgNPs (obtained from aqueous leaf extracts of Euphorbia sanguine) with $\mathrm{IC}_{50}$ of $71.96 \mu \mathrm{g} / \mathrm{ml}$ [34].The improved tyrosinase inhibition prompted further investigation of the kinetics of the inhibition and mode of inhibitor-tyrosinase interaction.

\subsubsection{Kinetics and type of tyrosinase inhibition}

The kinetics of interaction of the silver nanoparticles with mushroom tyrosinase and the mode of tyrosinase inhibition of the silver nanoparticles were investigated using Line-weaver - Burk model. The result of the Line-weaver - Burk (double displacement) plot was presented in Fig 8 .

\section{Fig 8: Line-weaver - Burk (double displacement) plot}


The results showed that in the absence of the nanoparticles, maximum velocity (Vmax) of the enzyme was calculated to be $0.32 \mathrm{mM} / \mathrm{min}$, while the affinity of the enzyme $(\mathrm{Km})$ for L-DOPA was found to be $1.071 \mathrm{mM}$. $\mathrm{Km}$ is described as the concentration that will be able to saturate $50 \%$ of the enzyme. On the introduction of an inhibitor $(50 \mu \mathrm{g} / \mathrm{L}$ of the AgNPs), the Vmax of the reaction was found to be $0.319 \mathrm{mM} / \mathrm{min}$ while the $\mathrm{Km}$ was calculated to be $2.01 \mathrm{mM}$. The result clearly showed that the Vmax of the reaction was not affected by the presence of the inhibitor but $\mathrm{Km}$ was increased compared to the former. This type of occurrence is typical of competitive mode of inhibition where the inhibitor and substrate compete for the active site of the enzyme. The mechanism of action involves the biogenic AgNPs inhibiting the substrates from binding to the active site of the mushroom tyrosinase enzyme, thereby preventing tyrosinase L-DOPA oxidation.

The inhibition constant $\mathrm{Ki}$ of the AgNPs (inhibitor) represents the concentration at which 50\% of the tyrosinase enzymes would have transformed to enzyme - inhibitors complex form. The inhibition constant (Ki) was calculated using the lineweaver - Burk plot for the competitive plot equ (4) and (5)

$\therefore v_{o}=\frac{V_{\max }[S]}{K_{m}+([S])\left(1+\frac{[I]}{K_{I}}\right)}$

$\frac{1}{v}=\left(\frac{K_{m}}{V_{\max }}\right) \cdot \frac{1}{[S]}+\frac{1}{V_{\max }}\left(1+\frac{[I]}{K_{i}}\right)$

The inhibition constant was calculated as $0.289 \mathrm{mM}$. The initial velocity (Vo) of the enzyme was calculated at the substrate concentration of $0.1 \mathrm{mM}$ to be $0.027 \mathrm{mM} / \mathrm{min}$ in the absence of an inhibitor. However, in the presence of the AgNPs, it decreased to $0.00017 \mathrm{mM} / \mathrm{min}$, giving a relative activity of 0.006 and a percentage fractional inhibition of $99.37 \%$. Hence, the biosynthesized silvernanoparticles have good inhibitory effect on tyrosinase enzyme [33].

\subsection{Photocatalytic activity of the silver nanoparticles}

The photocatalytic degradation of malachite green (MG) dye solution was done in the presence and absence of the silver nanoparticles and under solar radiation. The adsorption spectrum of the 
malachite dye in aqueous solution shows adsorption max at $622 \mathrm{~nm}$ due to $n \rightarrow \pi *$ transition[35]. The relative absorbance of band at $622 \mathrm{~nm}$ is plotted as a function of time to evaluate the reduction reaction rate (Fig. 9) in the presence of silver nanoparticles.

\section{Figure 9: Absorption spectra of MG at different time intervals}

The decreasing trend of the absorption intensity indicates the degradation or mineralization of malachite green dye in the solution. During the degradation process, the intense green colour of MG solution faded and eventually became colourless with time.

Fig 10 shows that on exposure of the dye solution containing AgNPs to solar radiation, 86\% degradation was achieved in less than a min. The catalytic process proceeded in a much slower rate afterwards to achieve $94 \%$ in 60min of illumination from sunlight. In the absence of AgNPs the degradation process of MG proceeded very slowly compared to that obtained in the presence of AgNPs. In 24hrs, 20\% degradation of the dye was obtained. Hence, the increase in rate of the degradation process in the presence of AgNPs can be attributed to the photocatalytic ability of the nanoparticle.

\section{Figure 10: Percentage degradation of MG with time}

The results obtained from the photocatalytic study was an improvement to those reported in literature: Madiha and Nida (2018) reported 70\% degradation of malachite green after 120 minutes using copper nanoparticles; Fairuziet al (2018) reported 92\% degradation of methylene blue using silver nanoparticles; [32, 36, 37].

\subsubsection{Photocatalytic kinetics}

The photo-degradation kinetic data of MG using AgNPs was analyzed with the linear forms of first order and second order kinetic models. The equations for rate laws of the first order and second order kinetic models, as well as, their half-lives are shown in equations (6-9) [36].

$$
\begin{aligned}
& \ln \frac{A_{0}}{A_{t}}=k_{1} t \\
& \frac{1}{A_{t}}-\frac{1}{A_{0}}=k_{2} t
\end{aligned}
$$




$$
\begin{aligned}
& t_{1 / 2}=\frac{\ln 2}{k_{1}} \\
& t_{1 / 2}=\frac{1}{k_{2} A_{0}}
\end{aligned}
$$

Where $A_{0}$ is initial absorbance; $A_{t}$ is absorbance at time $t ; k_{1}$ and $k_{2}$ are rate constants for first order and second order reactions respectively; $\mathrm{t}_{1 / 2}$ is half-life.

Figure 11a shows the kinetic plot for the first order reaction, where $\ln A_{0} / A_{t}$ was plotted against time. A plot of $1 / A_{t}-1 / A_{0}$ against time can be seen in figure $11 \mathrm{~b}$ representing the second order kinetic model.

\section{Figure 11a: First order kinetics for degradation of MG Figure 11b: Second order kinetics for degradation of MG}

The correlation coefficient, $\mathrm{R}^{2}$ for the second order kinetic model was 0.9787 , which was slightly higher than that of the first order of 0.9702. This implies that second order kinetic model gave the best fit for the photo-degradation of MG dye solution using AgNPs in the study. Tolia

et al (2012) reported that pseudo-second order model gave the best fit for the photo-degradation of malachite green using doped and undoped $\mathrm{ZnS}$ nanoparticles [38]. Rate constants obtained for first order reaction and second order reaction are $0.0152 \mathrm{~min}^{-1}$ and $0.136 \mathrm{mM}^{-1} \mathrm{~min}^{-1}$ while the half-lives for both are $45.60 \mathrm{~min}$ and $40.18 \mathrm{~min}$ respectively.

\subsubsection{Mechanism of Photocatalytic activity}

The mechanism of photocatalysis for silver nanoparticles in the degradation of dye molecules involves the excitation of electrons from the valence band to the conduction band of the silver nanoparticles on absorption of energy under solar radiation. The excitation of electrons to higher energy states creates electron holes. The excited electrons interact with molecular oxygen in water and generate free radicals. The free radicals interact with the dye molecules causing reduction to occur, and thus, lead to mineralization of the dye to less hazardous byproducts. Subsequently, the electron holes created accept electrons from the adsorbed dye molecules and thereby oxidize them to byproducts like $\mathrm{CO}_{2}, \mathrm{H}_{2} \mathrm{O}$ and so on[39, 40]. 


\subsubsection{Antibacterial studies}

The antibacterial activities of aqueous leaf extract of A.laxiflora, $\mathrm{AgNPs}$ and $\mathrm{AgNO}_{3}$ were studied using Gram negative (Escherichia coli) and Gram positive (Staphylococcus aureus) isolates. The samples exhibited antibacterial properties at a concentration of $10 \mu \mathrm{g} / \mathrm{mL}$. The zones of inhibition exhibited by the leaf extract against the test bacteria ranged between $12 \mathrm{~mm}$ and $24 \mathrm{~mm}$ for E.coli and S.aureus respectively. The AgNPs showed improved zones of inhibition compared to the plant extracts and $\mathrm{AgNO}_{3}$ at $20 \mathrm{~mm}$ and $28 \mathrm{~mm}$ for E.coli and S.aureus respectively. Streptomycin showed zones of inhibition in the range of $24 \mathrm{~mm}$ and $30 \mathrm{~mm}$ for E.coli and S.aureus strains respectively. The MIC of AgNPs against test bacteria strains ranged between $1 \mu \mathrm{g} / \mathrm{mL}$ and $3 \mu \mathrm{g} / \mathrm{mL}$ for the Escherichia coli and Staphylococcus aureus isolates respectively. The variation in the antibacterial activity of the samples against the two isolates could be partly due to differences in cell wall composition of the strains which affect cell permeability of the samples.

The results of the antibacterial screening of the AgNPs were better than those reported in literature for AgNPs obtained from aqueous extract of gum kondagogu and corn leaf waste of Zea mays with MIC of 2 and $10 \mu \mathrm{g} / \mathrm{mL}$; and 50 and $12.5 \mu \mathrm{g} / \mathrm{mL}$ for E.coli and S.aureus respectively.

\subsection{CONCLUSION}

In the present study, silver nanoparticles were synthesized by making use of aqueous leaf extract of A.laxiflora. The AgNPs showed good antibacterial potentials against E.coli and S.aureus isolates with MIC of $0.5 \mu \mathrm{g} / \mathrm{mL}$ and $3 \mu \mathrm{g} / \mathrm{mL}$ respectively. A photocatalytic efficiency of $86 \%$ dye degradation was achieved in less than a min for the degradation of malachite green dye solution, at a rate of $0.136 \mathrm{~min}^{-1}$ under a second order kinetics. Also, the AgNPs exhibited a dose dependent tyrosinase inhibition activity with $\mathrm{IC}_{50}$ of $20.83 \mu \mathrm{g} / \mathrm{ml}$ in a competitive manner with the substrate. The study achieved threefold purpose silver nanoparticles using a simple, ecofriendly and economic plant mediated process.

\section{Acknowledgement}

The authors are grateful to Alex Ekwueme Federal University Ndufu-Alike, Nigeria for the provision of laboratory space and equipments. 


\section{Declaration of interests}

The authors declare that they have no known competing financial interests or personal relationships that could have appeared to influence the work reported in this paper.

\section{REFERENCES}

1. S. Kamaljit and A. Sucharita. Removal of Synthetic Textile Dyes From Wastewaters: A Critical Review on Present Treatment Technologies. Critical Reviews in Environmental Science and Technology, 41: 9 (2011) 807 - 878. DOI: 10.1080/10643380903218376.

2.M. A. Hassaan, A. El-Nemr. Health and Environmental Impacts of Dyes: Mini Review. American Journal of Environmental Science and Engineering, 1:3 (2017) 64-67. DOI: 10.11648/j.ajese.20170103.11

3. L. David and B. Moldovan. Green Synthesis of Biogenic Silver Nanoparticles for Efficient Catalytic Removal of Harmful Organic Dyes. Nanomaterials, 10 (2020) 202-212. DOI:10.3390/nano10020202.

4. B. Dhananjay, V. G. Pangarkar, A.A.C.M Beenackers. Photocatalytic Degradation for Environmental Application-A Review. Journal of Chemical Technology \& Biotechnology, 77:1 (2002) 102 - 116. DOI: $\underline{10.1002 / j c t b .532 .}$

5. S. Joseph, B. Mathew. Microwave assisted green synthesis of silver nanoparticles in the study on catalytic activity in the degradation of dyes. J. Mol. Liq., 204 (2015) 184-191. https://doi.org/10.1016/j.molliq.2015.01.027

6. O. Danila; A. Berghian-Sevastre; V. Dionisie; D. Gheban; D. Olteanu; F. Tabaran; I. Baldea; G. Katona; B. Moldovan; S. Clichici. The effects of silver nanoparticles on behavior, apoptosis and nitro-oxidative stress in offspring Wistar rats. Nanomedicine, 12 (2017) 1455-1473. https://doi.org/10.2217/nnm-2017-0029.

7. N. Chandrasekhar; S.P. Vinay. Yellow colored blooms of Argemone mexicana and Turnera ulmifolia mediated synthesis of silver nanoparticles and study of their antibacterial and 
antioxidant activity. Appl Nanosci.,7 (2017) 851-861. https://doi.org/10.1007/s13204-017-0624$\underline{5}$.

8. O. Choi, K.K. Deng, N.J. Kim, I. Rossjr, R.Y. Surampalli and Z. Hu. The inhibitory effects of silver nanoparticles, silver ions and silver chloride colloids on microbial growth. Water Research, 42:12 (2008) 3066-3074. https://doi.org/10.1016/j.watres.2008.02.021.

9. E. E. Elemike, D.C. Onwudiwe, D.F. Ogeleka, J.I. Mbonu. Phyto-assisted preparation of Ag and $\mathrm{Ag}-\mathrm{CuO}$ nanoparticles using aqueous extracts of Mimosa pigra and their catalytic activities in the degradation of some common pollutants. Journal of Inorganic and Organometallic Polymer and Materials. 2019. https//doi.org/10.1007/s10904-019-01142-y.

10. V.K. Vidhu, and D. Philip. Catalytic degradation of organic dyes using biosynthesized silver nanoparticles. Micron, 56 (2014.) 54-62. doi: 10.1016/j.micron.2013.10.006.

11. G.G. Selvam; K. Sivakumar. Phytosynthesis of silver nanoparticles and photocatalytic degradation of methyl orange dye using silver ( $\mathrm{Ag}$ ) nanoparticles synthesized from Hypnea musciformis (Wulfen) J.V. Lamouroux. Appl Nanosci, 5 (2015) 617-622. DOI 10.1007/s13204014-0356-8.

12. B. Kumar; K.S. Vizuete; V. Sharma; A. Debut; L. Cumbal. 2019. Ecofriendly synthesis of monodispersed silver nanoparticles using Andean mortiñoberry as reductantand its $\begin{array}{llll}\text { photocatalytic } & \text { activity. Vacuum, } 160 \quad 272-278 .\end{array}$ https://doi.org/10.1016/j.vacuum.2018.11.027.

13. N. Basavegowda, A. Idhayadhulla, Y.R. Lee. Tyrosinase inhibitory activity of silver nanoparticles treated with Hovenia dulcis fruit extract: An invitro study. Materials Letters, 129 (2014) 28-30. doi:10.1016/j.matlet.2014.05.008.

14. R. K. Raajshree, B. Durairaj. Evaluation of the antityrosinase and antioxidant potential of zinc oxide nanoparticles synthesized from the brown seaweed-Turbinaria conoides. International $\begin{array}{lllll}\text { journal of } & \text { applied } & \text { pharmaceutics, } & 9: 5 & \text { (2017). }\end{array}$ http://dx.doi.org/10.22159/ijap.2017v9i5.20847. 
15. C.O. Tettey, P.C. Nagajyothi, S.E. Lee, A. Ocloo, T.N.A. Minh, T.V.M. Sreekanth and K. D. Lee. Anti-melanoma, tyrosinase inhibitory and anti-microbial activities of gold nanoparticles synthesized from aqueous leaf extracts of Teraxacum officinale. International Journal of Cosmetic Science, 34 (2012) 150-154. doi: 10.1111/j.1468-2494.2011.00694.x.

16. A.C. Ekennia; N.N. Nwaji; D.N. Uduagwu; O.J. Olowu; O.L. Nwanji; O.O. Oje; B. Daniel; S.I. Mgbii; C. Emma-Uba. Biosynthesis of zinc oxide nanoparticles using leaf extracts of Alchornea laxiflora and its tyrosinase inhibition and catalytic studies. Micron. (2020). https://doi.org/10.1016/j.micron.2020.102964.

17. D.A. Akinpelu, E.O. Abioye, O.A. Aiyegoro, O.F. Akinpelu, A.I. Okoh. Evaluation of Antibacterial and Antifungal Properties of Alchornea laxiflora (Benth.) Pax. \& Hoffman. Evidence-based Complementary and Alternative Medicine : Ecam, (2015) DOI: $\underline{10.1155 / 2015 / 684839}$.

18. E. O. Farombi, O.O Ogundipe, E. S. Uhunwangho, M.A. Adeyanju, J. O. Moody. Antioxidant properties of extracts from Alchornea laxiflora (Benth) Pax and Hoffman. Phytother Res. 2003 Aug;17(7):713-6. doi: 10.1002/ptr.1050.

19. O.J. Jayeoba; H.M. Ijeomah; I.M. Ogara. Ethnomedical utilization of alchornea laxiflora (benth) Pax \& K Hoffm in Irepodun/Ifelodun local government area of Ekiti state, southwest, Nigeria. Journal of Agriculture and Social Research. Vol. 12 No. 2 (2012)

20. A.A. Olajire, N.F. Ifediora, M.D. Bello. Green Synthesis of Copper Nanoparticles Using Alchornea laxiflora Leaf Extract and Their Catalytic Application for Oxidative Desulphurization of Model Oil. Iran J Sci Technol Trans Sci. 42 (2018) 1935-1946. https://doi.org/10.1007/s40995-017-0404-9.

21. S. Bhakya, S. Muthukrishman, M. Sukumaran, M. Muthukumar, T. S. Kumar, M.V. Catalytic degradation of organic dyes using synthsized silver nanoaprticles: a green approach. J. Bioremed. Biodegr. 6 (2015) 1-9. doi:10.4172/2155-6199.1000312

22. E. E. Elemike, D. C. Onwudiwe, A.C. Ekennia, L. Katata-Seru. Biosynthesis, characterization, and antimicrobial effect of silver nanoparticles obtained using Lavandula $\times$ 
intermedia. Research on Chemical Intermediates 43:3 (2017) 1383-1394. DOI: 10.1007/s11164016-2704-7.

23. E.E. Elemike, D.C. Onwudiwe, A.C. Ekennia, R.C. Ehiri, N.J. Nnaji. Phytosynthesis of silver nanoparticles using aqueous leaf extracts of Lippiacitriodora: Antimicrobial, larvicidal and photocatalytic evaluations. Materials Science and Engineering C. 75 (2017) 980-989.

24. M.L. Curri, R. Comparelli, P.D. Cozzoli, G. Mascolo, and A. Agostiano. Colloidal oxide nanoparticles for the photocatalytic degradation of organic dye. Materials Science and Engineering, 23 (2003) 285-289. https://doi.org/10.1016/S0928-4931(02)00250-3

25. O. Ogundipe, J. Moody, P. Houghton, H.A Odelola. Bioactive chemical constituents from Alchornea laxiflora (benth) Pax and Hoffman, Journal of Ethnopharmacology, 74:3 (2001) 275280. https://doi.org/10.1016/S0378-8741(00)00352-4

27. M. Yildiztekin, S. Nadeem, F. Yildiztekin, Ö. Varol, M. A. Özler and A. L. Tuna. 2017.Green Synthesis and Characterization of Silver Nanoparticles from Crocus Mathewii; A Disremembered Turkish Flowering Plant. Indian J. Pharm Sci. 79:4 (2017) 536-543. DOI: 10.4172/pharmaceutical-sciences. 1000260

28. G. Bagherzade, M.M. Tavakoli, M.H. Namaei. Green synthesis of silver nanoparticles using aqueous extract of saffron (Crocus sativus $\mathrm{L}$.) wastages and its antibacterial activity against six $\begin{array}{lllllll}\text { bacteria. Asian Pac J } & \text { Trop }\end{array}$ 33.http://dx.doi.org/10.1016/j.apjtb.2016.12.014

29. R. R. Banala, V. B. Nagati, P. R. Karnati. 2015. Green synthesis and characterization of Carica papaya leaf extract coated silver nanoparticles through X-ray diffraction, electron microscopy and evaluation of bactericidal properties. Saudi Journal of Biological Sciences, 22: 5 (2015) 637-644. https://doi.org/10.1016/j.sjbs.2015.01.007

30. A.M.H. Majles, Z. Dehghani, R. Sahraei, A. Daneshfar, Z. Javadi and F. Divsar. Diffraction patterns and nonlinear optical properties of gold nanoparticles, J. Quantitative Spectroscopy and $\begin{array}{llll}\text { Radiative } & \text { Transfer, } & 113: 5 & \text { (2012) 366-372. }\end{array}$ https://doi.org/10.1016/j.jqsrt.2011.12.006 
31. K. Khanra, S. Panja, I. Choudhuri, A. Chakraborty, N. Bhattacharyya. Evaluation of Antibacterial Activity and Cytotoxicity of Green Synthesized Silver Nanoparticles Using Scoparia Dulcis. Nano Biomed Eng.,7:3 (2015) 128-133. DOI: 10.5101/nbe.v7i3.p128-133

32. M. Batool \& N. Mehboob. Degradation of Malachite Green by Green Synthesized Copper Nanoparticles by Using Aloe Barbadensis Leaf Extracts, Archives Of Nanomedicine, 1:2 (2018) 29-34. DOI: 10.32474/ANOAJ.2018.01.000108.

33. Q. Abbasa, M. Saleemb, A. R. Phull, M. Rafiq, M. Hassan, L. Ki-Hwan and S. Sung-Yum. Green Synthesis of Silver Nanoparticles using Bidens Frondosa Extract and their Tyrosinase Activity. Iranian Journal of Pharmaceutical Research, 16:2 (2017) 760-767. PMID: 28979330

34. A.C. Ekennia; D.N. Uduagwu; N. N. Nwaji; O. J. Olowu; O. L. Nwanji; M. Ejimofor; C. U. Sonde; O.O. Oje; D. O. Igwe. Green synthesis of silver nanoparticles using leaf extract of Euphorbia sanguine: An invitro study of its Photocatalytic and Melanogenesis inhibition activity. Inorganic and Nano-metal Chemistry. 2020.https://doi.org/10.1080/24701556.2021.1891100.

35. M. Magdalane, K. Kaviyarasu, J.J. Vijaya, C. Jayakumar, M. Maaza, B. Jeyaraj. Photocatalytic degradation effect of malachite green and catalytic hydrogenation by UVilluminated $\mathrm{CeO} 2 / \mathrm{CdO}$ multilayered nanoplatelet arrays: Investigation of antifungal and antimicrobial activities. Journal of Photochemistry and photobiology. B, Biology, 169 (2017) 110-123. DOI: 10.1016/j.jphotobiol.2017.03.008

36. Y. Chiu, T.M. Chang, C. Chen, M. Sone and Y. Hsu. Mechanistic Insights into Photodegradation of Organic Dyes Using Heterostructure Photocatalysts. Catalysts, 9 (2019) 430-437. doi:10.3390/catal9050430.

37. A.A. Fairuzi, N.N. Bonnia, R.M. Akhir, M.A. Abrani and H.M. Akil. Degradation of methylene blue using silver nanoparticles synthesized from imperata cylindrica aqueous extract. IOP Conference Series: Earth and Environmental Science, 105 (2018). doi: 10.1088/17551315/105/1/012018. 
38. J.V. Tolia, M. Chakraborty and Z.V.P. Murthy. Photocatalytic degradation of Malachite Green dye using doped and undoped $\mathrm{ZnS}$ nanoparticles. Polish Journal of chemical Technology, 14:2 (2012) 16 - 21. DOI: $\underline{10.2478 / \mathrm{v} 10026-012-0065-6}$

39. S. Marimuthu, A. J. Antonisamy, S. Malayandi, K. Rajendran, T. Pei-Chien, A. Pugazhendhi, V.K. Ponnusamy. Silver nanoparticles in dye effluent treatment: A review on synthesis, treatment methods, mechanisms, photocatalytic degradation, toxic effects and mitigation of toxicity, Journal of Photochemistry \& Photobiology, B: Biology (2020), https://doi.org/10.1016/ j.jphotobiol.2020.111823

40. M. Vanaja, K. Paulkumar, M. Baburaja, S. Rajeshkumar, G. Gnanajobitha, C. Malarkodi, M. Sivakavinesan and G. Annadurai. Degradation of methylene blue using biologically synthesized silver nanoparticles. Bioorganic Chemistry and Applications. (2014). http://dx.doi.org10.1155/2014742346.

41. A. JyothiKora and R. B. Sashidhar. Biogenic silver nanoparticles synthesized with rhamnogalacturonan gum: Antibacterial activity, cytotoxicity and its mode of action. Arabian Journal of Chemistry, 11:3 (2018) 313-323.

42. J.K. Patra and B. Kwang-Hyun. Antibacterial Activity and Synergistic Antibacterial Potential of Biosynthesized Silver Nanoparticles against Foodborne Pathogenic Bacteria along with its Anticandidal and Antioxidant Effects. Front. Microbiol., 2017. https://doi.org/10.3389/fmicb.2017.00167 
Figures

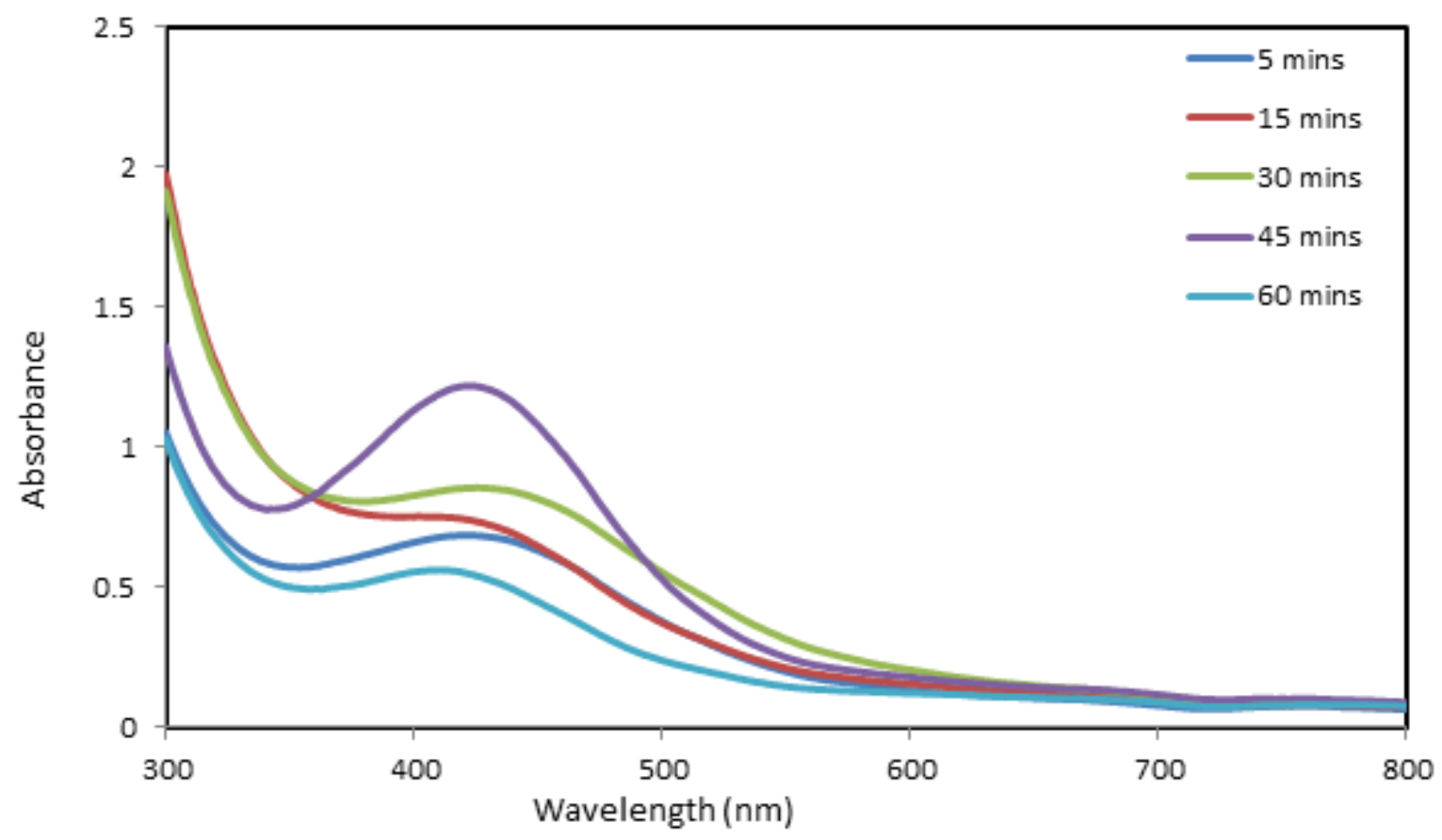

Figure 1

Effect of reaction time on the optical properties of the silver nanoparticles.

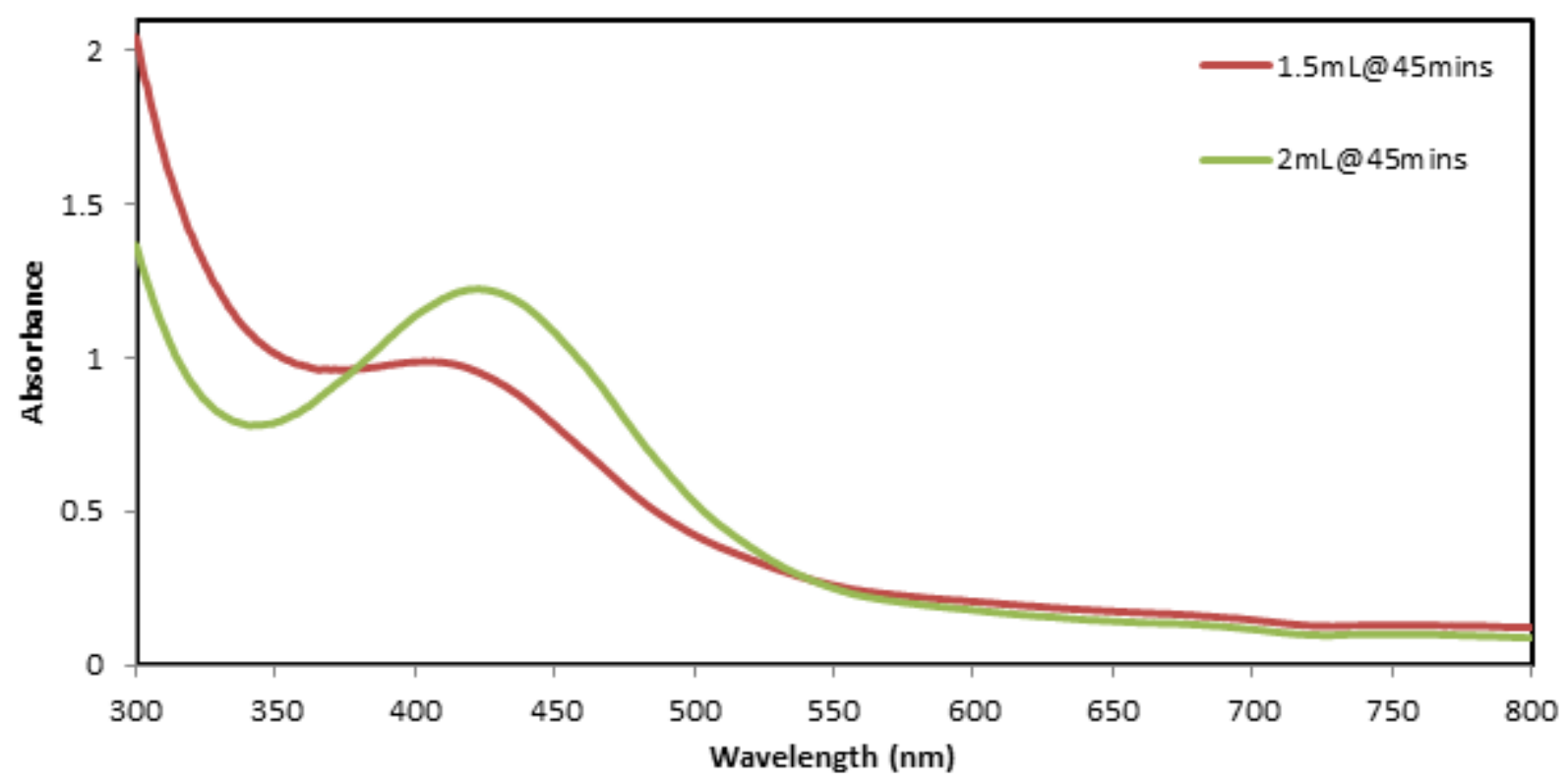

Figure 2

Effect of volume of leaf extract of Alchornea laxiflora on SPR band of the silver nanoparticles at 45min reaction time. 


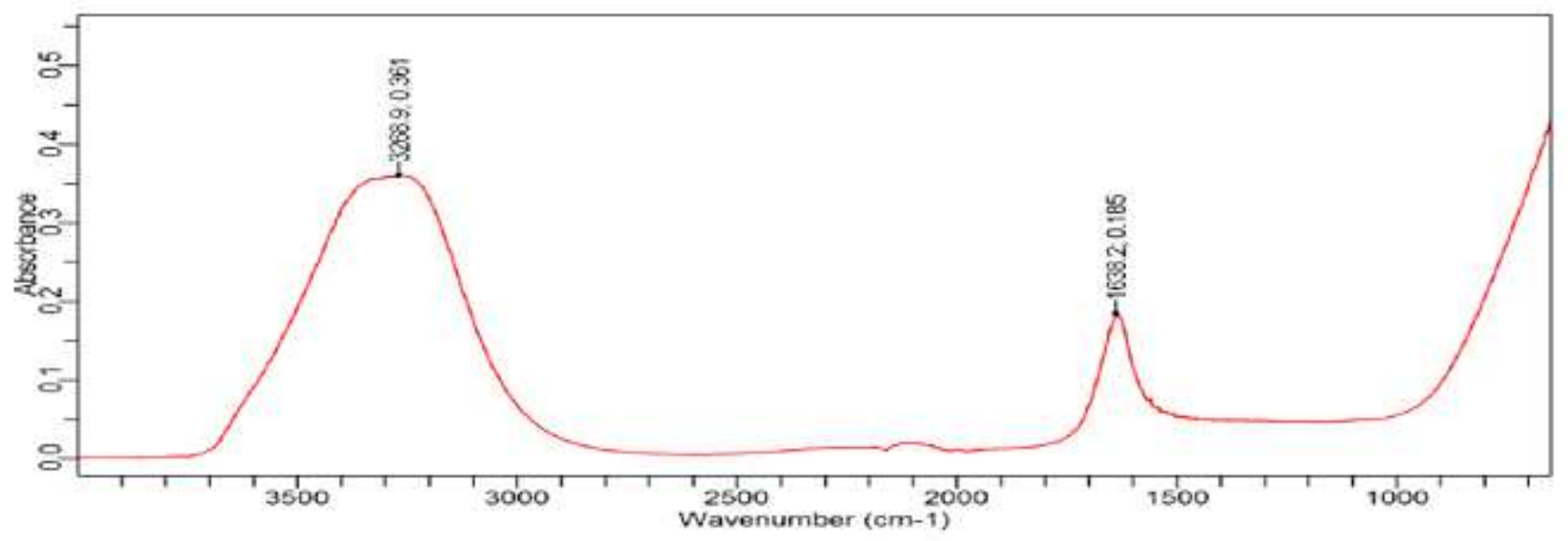

a.

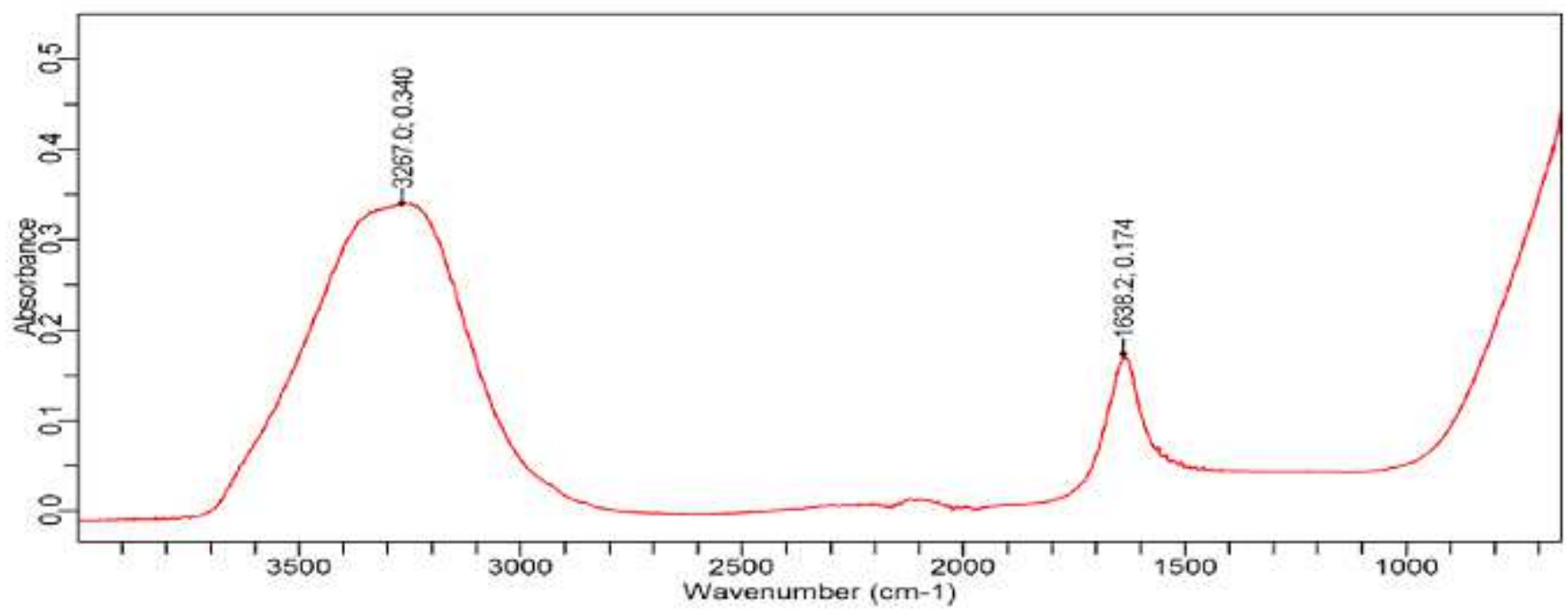

Figure 3

(a) FT-IR spectrum of aqueous leaf extract of Alchornea laxiflora (b) FT-IR spectrum of silver nanoparticles (AgNPs@45min).

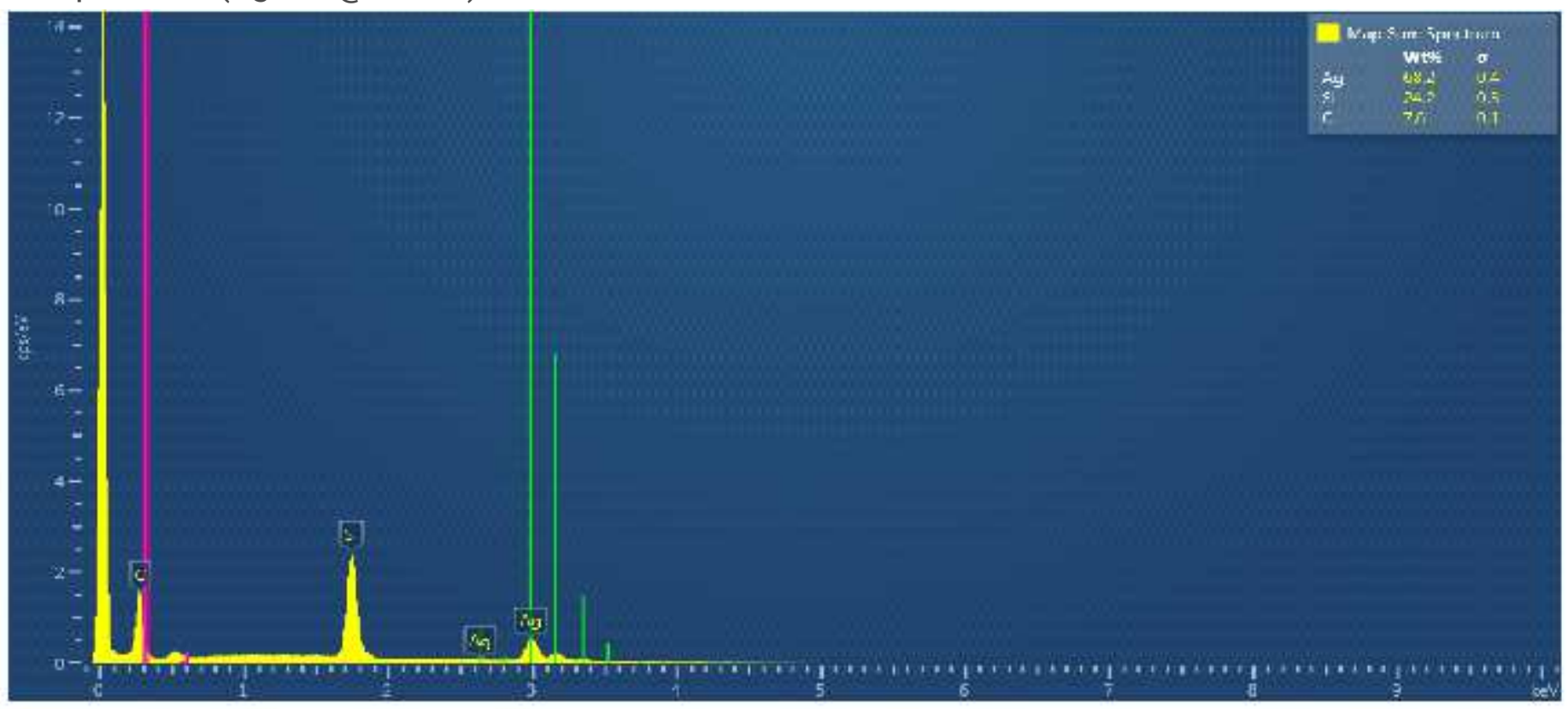


Figure 4

Energy dispersive X-ray of silver nanoparticles(AgNPs@45min)
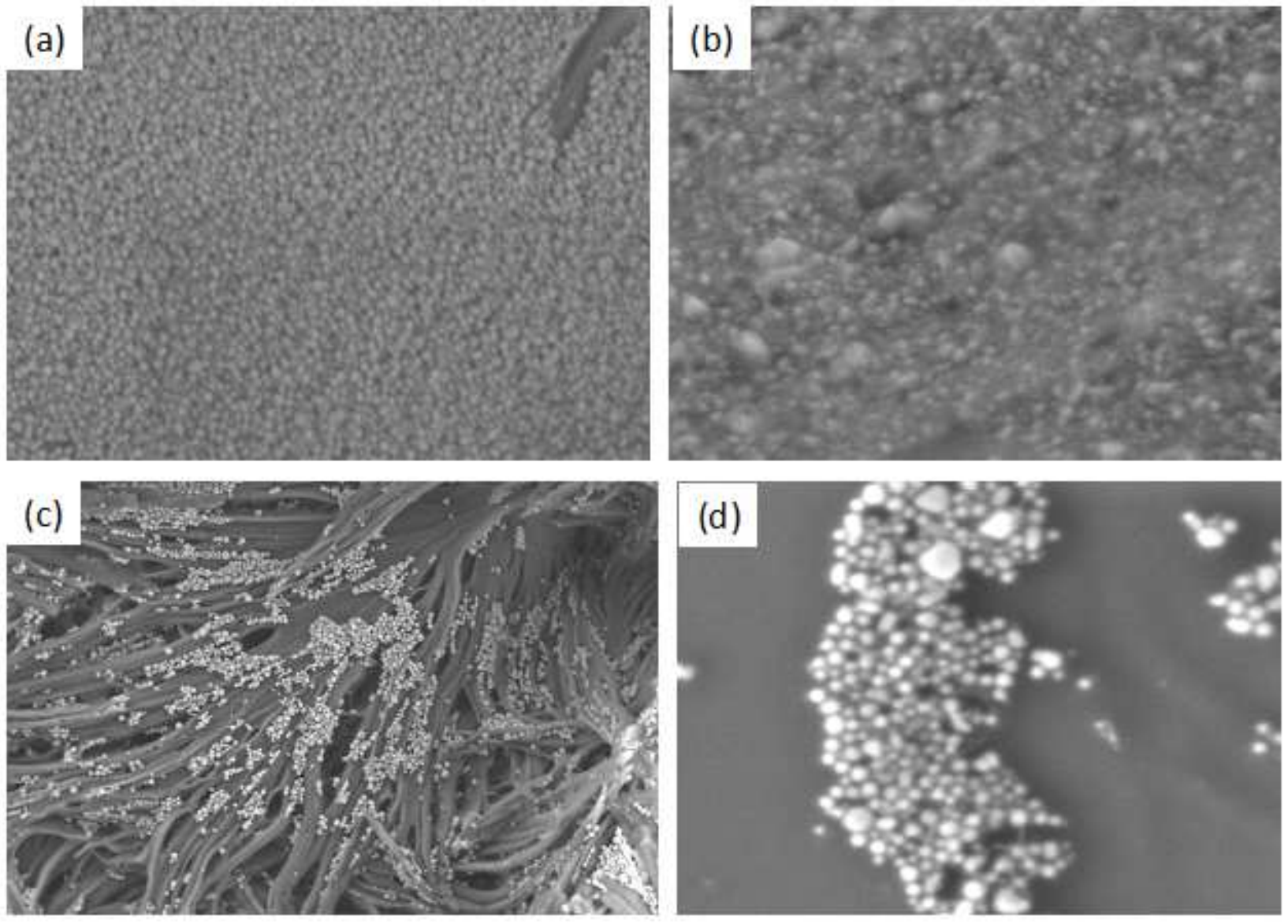

Figure 5

Scanning electron microscopic images of different silver nanoparticles(a).AgNPs@ 5 min(b). AgNPs@15 min (c).AgNPs@30 min (d).AgNPs@45min (Scale bar: 100 nm). 


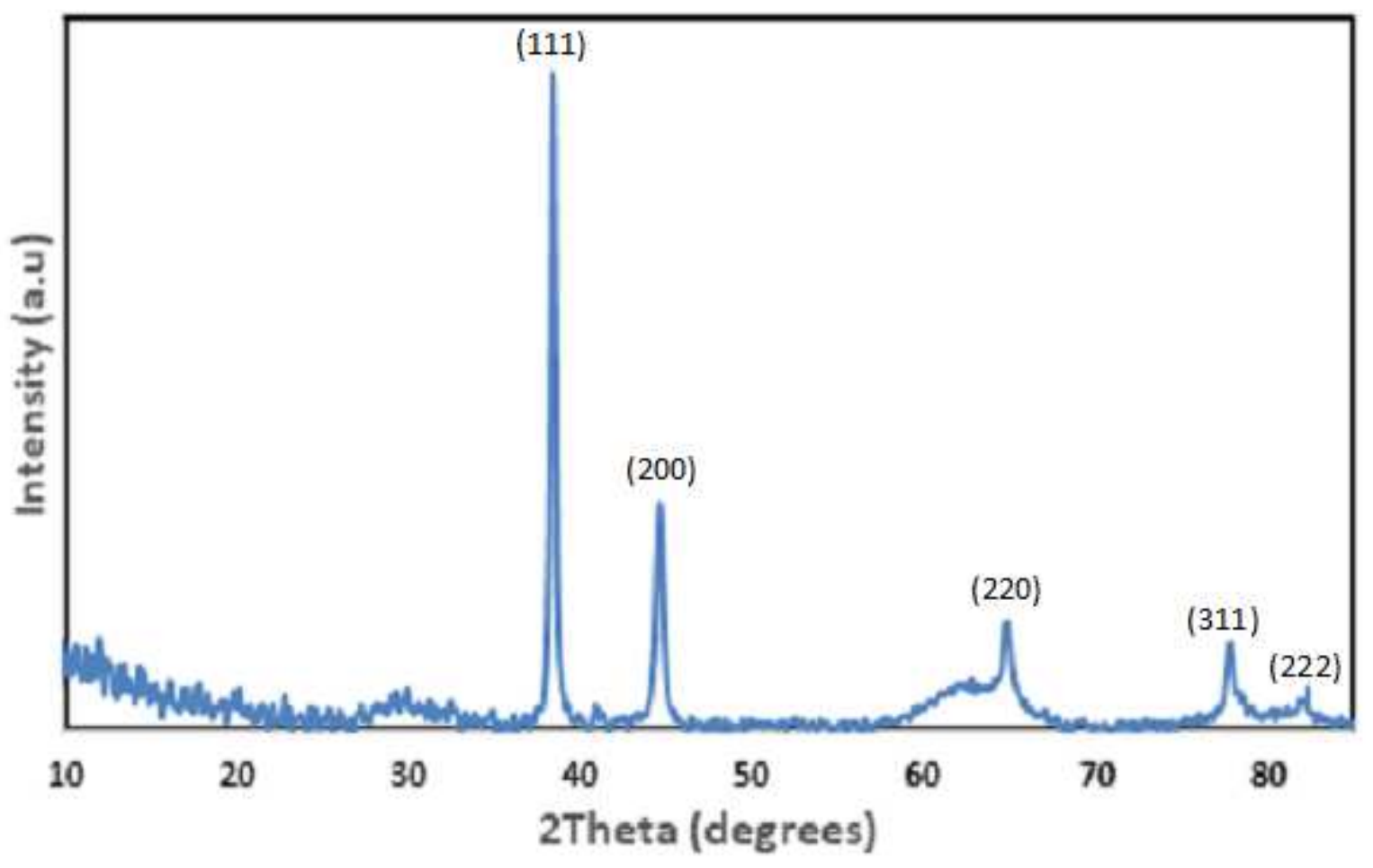

Figure 6

X-Ray Diffraction of silver nanoparticles (AgNPs@ 5min)

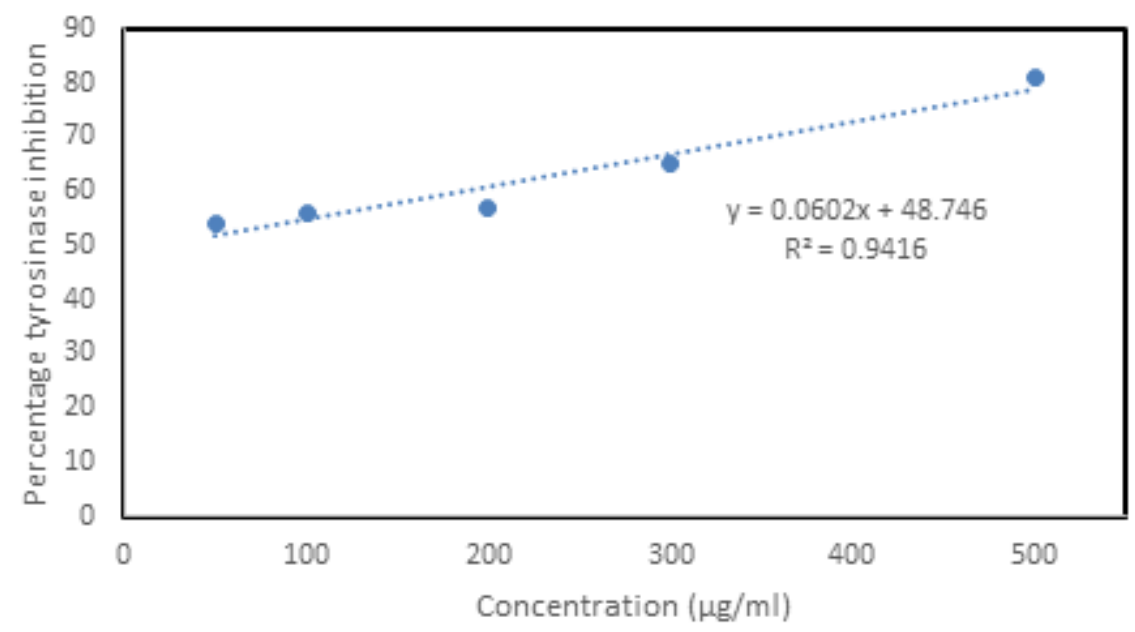

Figure 7

Tyrosinase inhibitory activity of AgNPs 


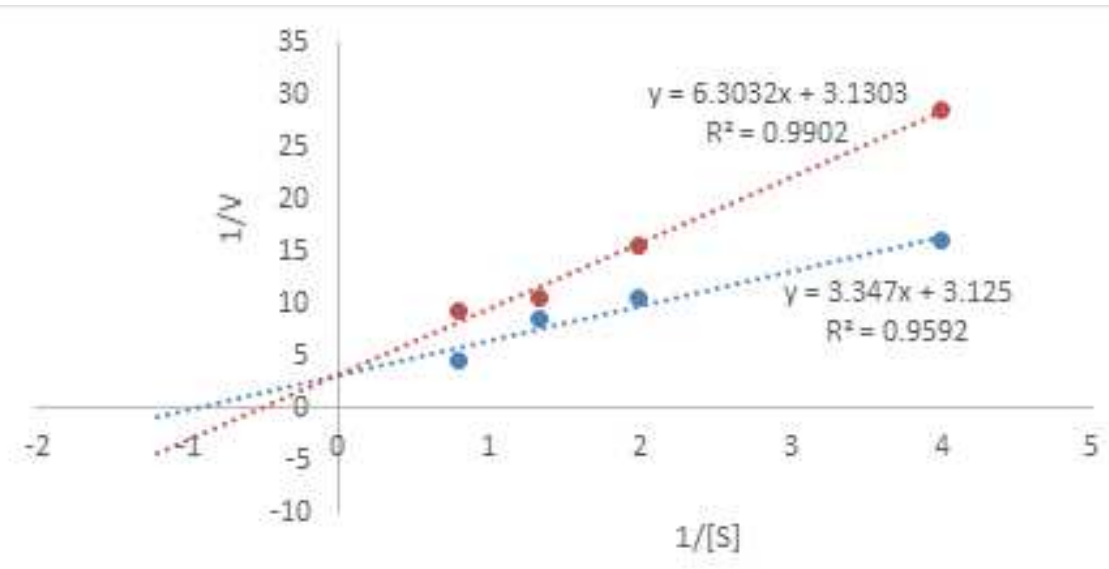

- 1/Vo - 1/V1 ......... Linear (1/Vo) .......... Linear (1/V1)

\section{Figure 8}

Line-weaver - Burk (double displacement) plot

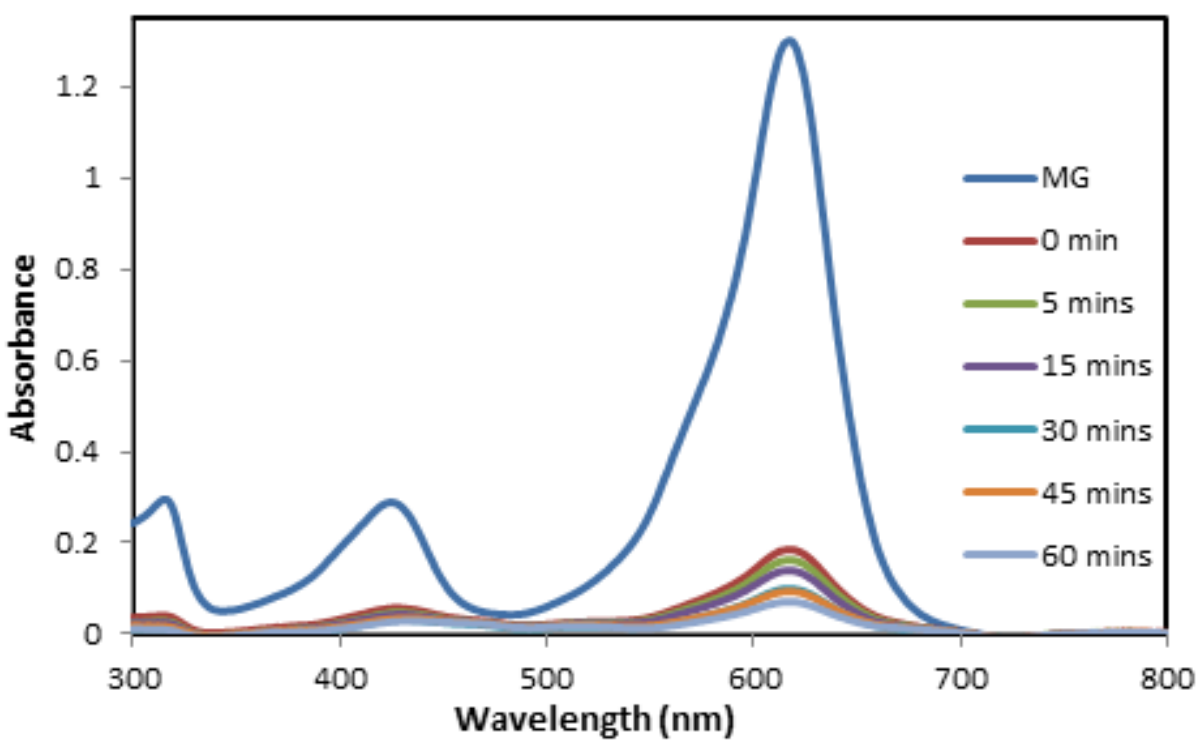

Figure 9

Absorption spectra of MG at different time intervals 


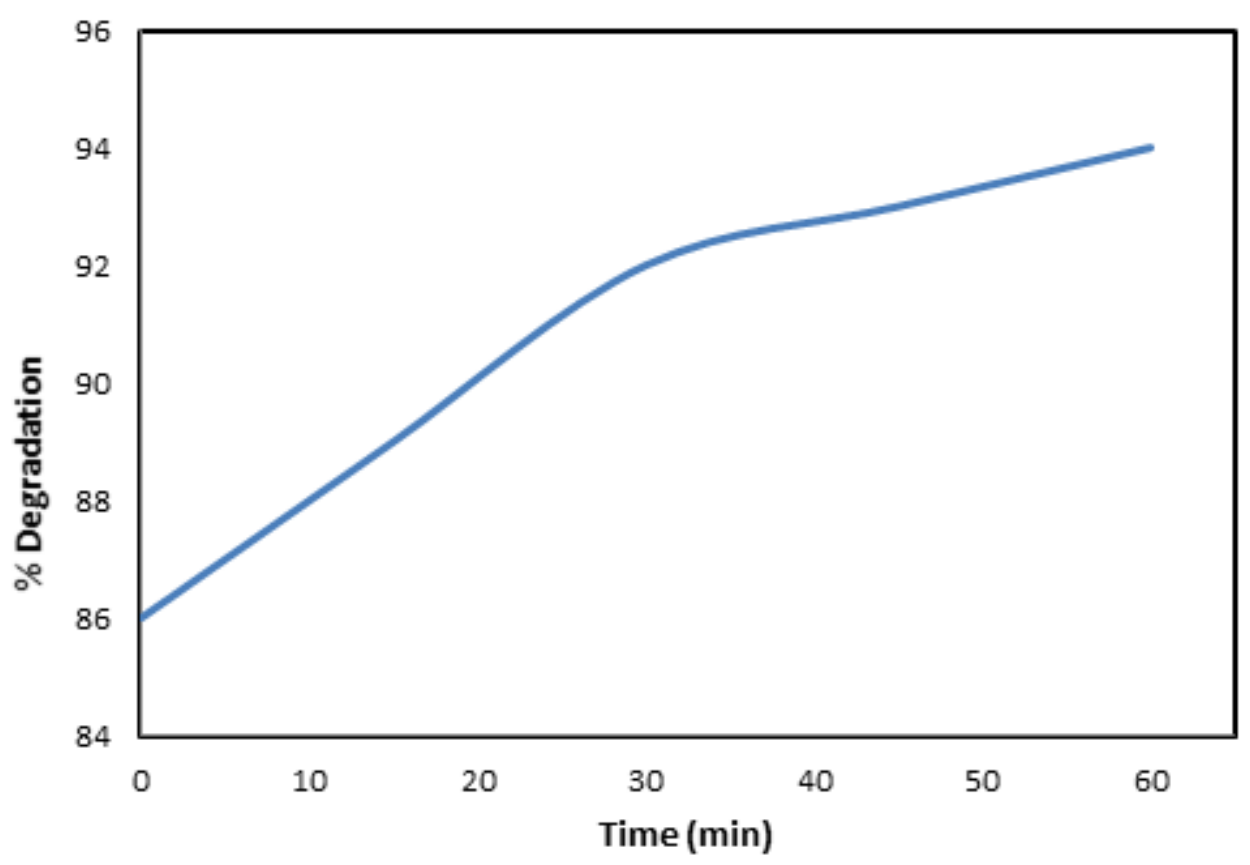

Figure 10

Percentage degradation of MG with time 

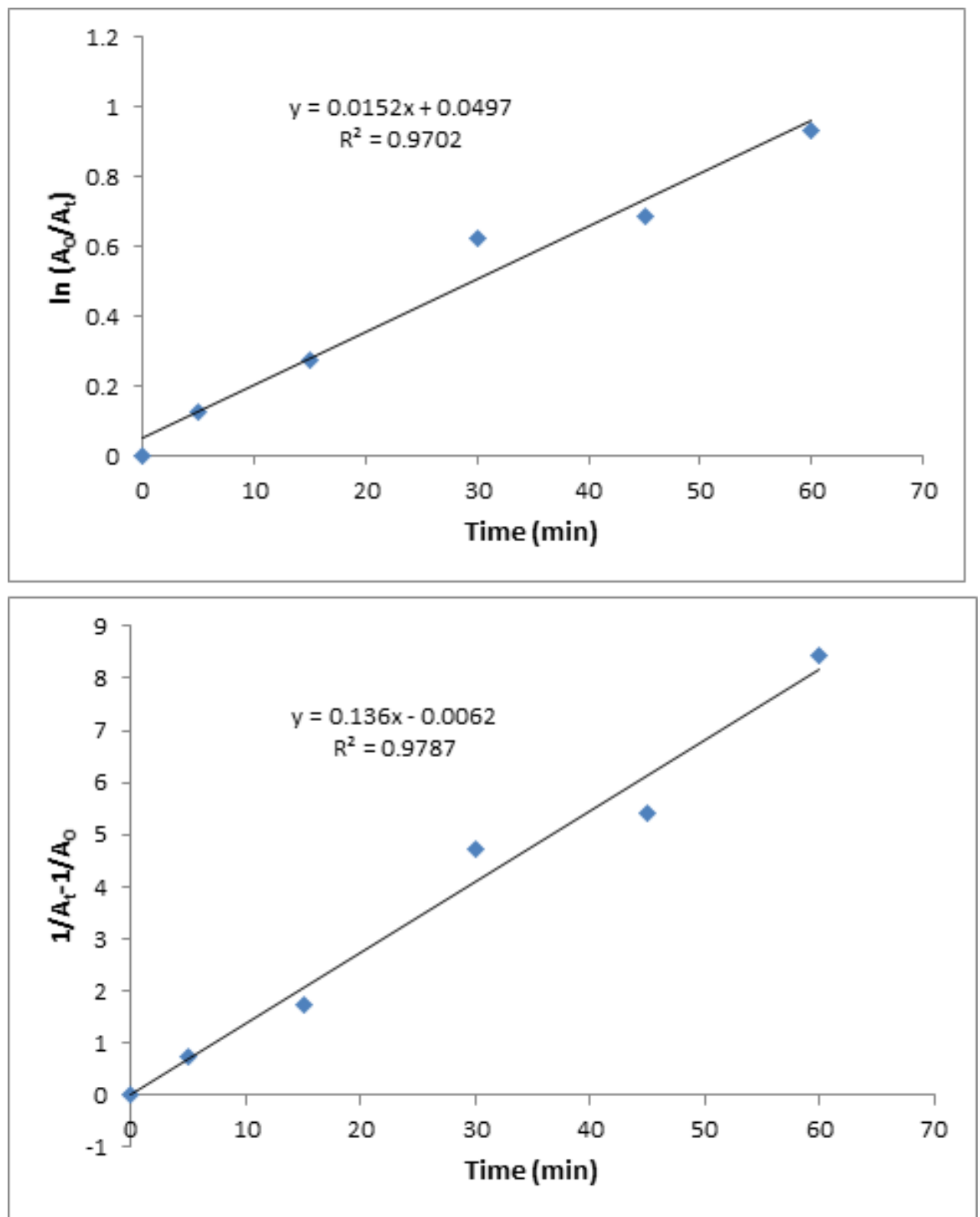

Figure 11

a: First order kinetics for degradation of MG b: Second order kinetics for degradation of MG 